\title{
Evaluation of the Clinical Learning Environment in Respiratory Therapy Education: Student Perceptions
}

\author{
Saeed M Alghamdi, Rayan A Siraj, and Arzu Ari
}

\begin{abstract}
BACKGROUND: Clinical facilities are essential components not only of health care delivery systems, but also of health care education programs. The clinical learning environment (CLE) is important in training the future health care workforce. Because respiratory therapy (RT) is a practice-based profession, it is essential to integrate clinical education into RT education. RT education programs face several issues with respect to the need for preparing a proper CLE in various clinical settings. The purpose of this study was to determine the perceptions of RT students on the CLE of clinical facilities affiliated with an RT program at an urban state university and to determine the impact of education level on student perception of the CLE of clinical facilities. METHODS: We used an exploratory research design to evaluate the essential aspects of a CLE in RT education. An adapted Clinical Learning Environment Supervision and Nurse Teacher $($ CLES + T) evaluation scale was utilized to evaluate 34 RT students' perceptions of clinical facilities in RT education; 32 students participated in the survey, with a response rate of $94.1 \%$. RESULTS: Responses included 2 groups of students: second-year undergraduates $(68.8 \%)$, in which women accounted for $81 \%$ and men $19 \%$, and graduate students $(31.2 \%)$, in which women accounted for $60 \%$ and men $40 \%$. Results obtained from the study indicated that both graduate and undergraduate RT students gave high median scores to the CLE, the supervisory relationship, and the role of clinical instructors. A statistically significant difference was obtained between the graduate and undergraduate students regarding multidimensional learning $(P=.043)$. We found that the majority of students positively rated the CLE in RT education. CONCLUSIONS: Education level influenced students' perceptions of the CLE of clinical facilities. Overall, respiratory therapy students rated their CLE experiences as positive and they were satisfied with the clinical instructor and team model. Key words: respiratory therapy; students; learning environment; teaching. [Respir Care 2019;64(2):161-168. (c) 2019 Daedalus Enterprises]
\end{abstract}

\section{Introduction}

The clinical environment has proven to be an essential component not only for the health care delivery system but

\footnotetext{
Mr Alghamdi is affiliated with the School of Physical and Occupational Therapy, McGill University, Montreal, Quebec, Canada. Mr Siraj is affiliated with the Department of Respiratory Medicine, University of Nottingham, Nottingham, England. Dr Ari is affiliated with the Department of Respiratory Care, Texas State University, Round Rock, Texas.

Supplementary material related to this paper is available at http:// www.rcjournal.com.

Dr Ari discloses relationships with the Chest Foundation, Bayer Pharmaceuticals, ARC Medical, Aerogen, and Sunovion Pharmaceuticals. $\mathrm{Mr}$ Siraj and Alghamdi has disclosed no conflicts of interest.
}

also for health care education programs. The clinical learning environment (CLE) is, in many respects, a fundamental facilitator for health care education. Respiratory therapy (RT) education programs, however, face challenges in providing a competent learning environment at some institutions. The clinical experience of respiratory therapy students varied among programs. These variations may include differences in clinical competencies expected at points throughout the curriculum, expectations of student

\footnotetext{
Correspondence: Saeed Alghamdi, School of Physical and Occupational Therapy, McGill University, 3654 Prom Sir-William-Osler, Montreal, Quebec, H3G 1Y5 Canada. E-mail: saeed.alghamdi2@mail.mcgill.ca.
}

DOI: $10.4187 /$ respcare. 05055 
performance, and evaluation processes and tools used during clinical education. This, in turn, greatly affects the knowledge and skills that are essential for work as a respiratory therapist. ${ }^{1}$

An effective CLE helps students understand the importance of teamwork, leading them to collaborate with other health care professionals while working with their fellow RT students to carry out duties in a timely fashion. These advantages are not achieved, however, if the CLE is ineffective or inappropriate. Failure to provide an effective CLE may create 2 principal problems: it can undermine the development of real-life and interpersonal skills in RT education, and future respiratory therapists may have a detrimental impact on the quality of patient care because they may not be as effective as their predecessors who received more comprehensive and effective clinical training. ${ }^{2}$ It is thus important to note that the CLE plays a critical role in the clinical education of students. ${ }^{3}$

Previous research has shown that learning outcomes are greatly affected by the CLE, which can be defined as an interactive system of certain influential factors. ${ }^{4-6}$ Graduates are expected to have sufficient clinical experience, theoretical knowledge, and technical skills required to work as a health care professional. It is essential that undergraduates in health care educational programs utilize any opportunity to nurture and develop practical clinical skills. Fieldwork, internships, clinical placements, and clinical practice are all components of clinical education that are essential for most health care education programs. ${ }^{7,8} \mathrm{Un}-$ fortunately, CLEs vary in terms of clinical settings as well as in terms of quality..$^{9,10}$

With the help of clinical placements, students have the opportunity to combine their didactic preparation with practical knowledge (ie, clinical skills) that is acquired during clinical education. This also helps students prepare for clinical practice that they might elect to pursue in their future careers. ${ }^{11}$ Hence, students are not only given the opportunity to fulfill their learning needs, but also learn from other students and health care professionals. ${ }^{12}$ Training at clinical sites inspires the students through relevant and active participation. ${ }^{13}$ According to a study conducted on nursing students' clinical environments, it was observed that the student's clinical professional development was greatly influenced by their interaction with hospital staff. ${ }^{14}$

There are many factors that influence the CLE, including the pedagogical atmosphere, the presumptions and principles of the instructors, and the student-supervisor relationship. ${ }^{15}$ All of these factors play a role in the relationship between learning outcomes and the CLE; in other words, these factors may have a significant impact on the student's adaptation and learning processes. ${ }^{16}$ While teaching effectiveness and behavioral characteristics of clinical instructors in RT education have been studied extensively, there is no study in the literature that evaluated the learn-

\section{QUICK LOOK}

\section{Current knowledge}

Clinical facilities are essential to providing high quality training of respiratory therapy students for the purpose of achieving clinical learning objectives. Previous research has demonstrated the importance of clinical learning environments for health professions and their effectiveness in helping students achieve learning goals.

\section{What this paper contributes to our knowledge}

Our results suggest that respiratory therapy students gave high median scores to the clinical learning environment, supervisory relationship, and the role of clinical instructors. All students felt supported and managed in clinical practice when they cooperated with the staff. However, they were unsatisfied with the clinical learning environment in terms of factors such as multidimensional learning conditions.

ing environment of clinical facilities in RT education. Thus, conducting research on the perceptions of RT students about clinical facilities would be beneficial to explore the effectiveness and influence of clinical facilities in respiratory therapy education. It would also help us determine where the facilities could benefit from further improvements.

The purpose of this study was to evaluate respiratory therapy students' perceptions of the learning environment of clinical facilities affiliated with an RT program at an urban state university. We also compared differences in perception between undergraduate and graduate students in terms of CLEs, supervisory relationships, and the role of instructors at clinical facilities. Upon investigating what has been written about the learning environment of clinical facilities in RT education, the following research questions arose:

1. How was the learning environment of clinical facilities affiliated with an urban university evaluated by RT students in terms of CLEs, supervisory relationships, and the role of the clinical instructors?

2. What were the differences between undergraduate and graduate students in terms of their perceptions of CLEs in RT education?

\section{Methods}

\section{Research Design and Instrument}

We used an exploratory research design to evaluate the essential aspects of CLE in RT education. A self-report 


\section{Student Perceptions of Clinical Learning Environments}

survey was utilized to gather data from RT students regarding their perceptions of the learning environments of clinical facilities. Clinical facilities play a major role in training RT students; therefore, this study evaluated medical centers, hospitals, and agencies that have been affiliated with a department of respiratory therapy at an urban university. All students receiving training at different clinical facilities were assigned to a clinical instructor or preceptor. Respiratory therapy students typically spend $224 \mathrm{~h}$ for 14 weeks at their clinical facilities every semester.

The Clinical Learning Environment Supervision and Nurse Teacher (CLES+T), an evaluation scale developed by Saarikoski et al, ${ }^{17}$ was used in this study. The CLES + T evaluation scale examines students' perceptions regarding the learning environment of clinical facilities. Because there is no instrument that can help us evaluate a CLE in respiratory therapy education, the CLES $+\mathrm{T}$ evaluation scale was adapted and modified after a written agreement from the author. We made the following modifications in the instrument: the term "nursing" was replaced with "respiratory therapy"; the term "general ward" was changed to "ICU"; and the term "nursing educator" was replaced with "clinical instructor." In addition, demographic data (eg, age, gender) were added to the survey. All modifications that were made in the CLES + T were approved by Saarikoski et al. ${ }^{17}$

The CLES + T evaluation scale was composed of 5 primary domains: pedagogical atmosphere (9 items), leadership style of RT manager (4 items), RT in ICUs (4 items), the content of supervision ( 8 items), and the role of clinical instructors (9 items). A Likert scale was used to capture student perceptions about the CLE in RT education. The scores utilized in the Likert scale were as follows: fully disagree; disagree to some extent; neither agree nor disagree; agree to some extent; and fully agree.

According to Saarikoski et al, ${ }^{17,18}$ the CLES + T evaluation scale is valid and reliable. Validity of the instrument was evaluated with Exploratory Factor Analysis and principal components analysis. The reliability of each subdimension was analyzed using Cronbach's alpha coefficient $(\mathrm{r}=0.94) .{ }^{18}$

\section{Sample}

The convenience sample of this study included secondyear RT students in the undergraduate and integrated master's degree programs at an urban university in southeastern United States. The sample size was 34 students, of whom 32 participated (94.1\% response rate) (see the supplementary materials at http://www.rcjournal.com).

Inclusion criteria were second-year RT students who had at least 2 rotations at different clinical facilities. Firstyear RT students and second-year RT students who had 2 clinical rotations at the same clinical facility were ex- cluded. Students who had clinical training at $>2$ clinical facilities were selected to capture their perception of the effectiveness of clinical facilities in RT education. Having clinical experiences at various clinical facilities helps students improve their perspective regarding CLEs, supervisory relationships, and the roles of the clinical instructor in the intensive care rotation.

\section{Data Collection and Statistical Analysis}

After IRB approval from Georgia State University and informed consent from all participants, data were collected from the questionnaire. Analysis was performed using the Statistical Package for the Social Sciences version 23 (SPSS, Chicago, Illinois). Descriptive statistics including frequency, percentage, median, and interquartile ranges were utilized to evaluate the learning environment of clinical facilities affiliated with an urban university based on students' perceptions of the respiratory therapy program. In addition, Mann-Whitney $U$ tests were used to compare perceptional differences between undergraduate and graduate students in terms of CLEs, supervisory relationships, and roles of clinical instructors at clinical facilities.

\section{Results}

Responses included 2 groups of students: second-year undergraduate students, $(68.8 \% ; n=22$ out of 32 participants), and graduate students $(31.2 \% ; n=10$ out of 32 participants) in their second year in the integrated master's degree program. Of the 32 participants, $75 \%$ were women. Ages (mean $\pm \mathrm{SD}$ ) for undergraduate and graduate students were $24.56 \pm 3.1 \mathrm{y}$ and $27.70 \pm 2.9 \mathrm{y}$, respectively (Table 1).

\section{Evaluation of the Learning Environment of Clinical Facilities}

We recorded frequency and percentage as well as median scores and interquartile ranges of the 3 domains (ie, the learning environment of clinical facilities, the content of supervision, and the role of clinical instructors) (see the supplementary materials at http://www.rcjournal.com). The learning environment of clinical facilities was evaluated based on pedagogical atmosphere, leadership style, and respiratory care in the ICU (Table 2). The majority of the undergraduate and graduate students felt comfortable going to the ICU at the start of their shift and thought that there were positive, sufficient, and meaningful learning situations in the ICU with staff, who were personable and easy to approach. Undergraduate student evaluations of clinical facilities revealed that these students felt somewhat less comfortable taking part in discussions during 
Table 1. Demographic Data of Undergraduate and Graduate Students, Occupational Title of Their Clinical Supervisor, Occurrence of Supervision and Private Supervision

\begin{tabular}{|c|c|c|}
\hline Demographics & Undergraduate & Graduate \\
\hline Age, y & $24.56 \pm 3.1$ & $27.70 \pm 2.9$ \\
\hline Female, $n(\%)$ & $18(81)$ & $6(60)$ \\
\hline \multicolumn{3}{|l|}{ Occupational title of clinical supervisor } \\
\hline Respiratory therapist & 81 & 80 \\
\hline Respiratory & 13 & N/A \\
\hline Clinical instructor & 4 & 20 \\
\hline \multicolumn{3}{|l|}{ Occurrence of supervision } \\
\hline $\begin{array}{l}\text { The relationship with named supervisor } \\
\text { did not work during the placement }\end{array}$ & 4 & 10 \\
\hline $\begin{array}{l}\text { The supervisor varied according to shift } \\
\text { or place of work }\end{array}$ & 68 & 10 \\
\hline $\begin{array}{l}\text { It was a group supervisor rather than } \\
\text { an individual supervisor }\end{array}$ & 10 & 20 \\
\hline $\begin{array}{l}\text { The relationship with named supervisor } \\
\text { worked during this placement }\end{array}$ & 18 & 60 \\
\hline \multicolumn{3}{|l|}{ Private supervision } \\
\hline Not at all & 27 & 40 \\
\hline Once or twice during the course & 36 & 10 \\
\hline Less than once a week & 4 & 30 \\
\hline About once a week & 10 & 20 \\
\hline More often & 22 & N/A \\
\hline \multicolumn{3}{|c|}{$\begin{array}{l}N=32 \text { students ( } n=22 \text { undergraduate students; } n=10 \text { graduate students). Data are shown as } \\
\text { mean } \pm \mathrm{SD}, n(\%) \text {, or as a percentage. }\end{array}$} \\
\hline
\end{tabular}

staff meetings before shifts, and that they felt the staff were only moderately interested in student supervision.

As a second domain of the CLE, undergraduate and graduate student evaluations of the overall leadership style adopted by the ICU manager were generally good. The leadership style of the ICU manager as a team member was given the highest ranking $(59.1 \%)$ by undergraduate students among all other statements in this section. The leadership style of the ICU manager as a leader who appreciated individual efforts was ranked as $70 \%$ by graduate students.

The third domain of the CLE was respiratory care given in the ICU of the clinical facilities, ranked in the order of opinion as given by the students. We found very positive undergraduate student evaluations $(68.2 \%)$, indicating that patients received individualized respiratory care and that documentation of respiratory therapy was clear $(63.6 \%)$. Similarly, graduate student evaluations returned a high percentage for both items, $80 \%$ and $70 \%$, respectively.

\section{Evaluation of the Content Supervision at Clinical Facilities}

The fourth domain pertained to supervision in clinical facilities. Undergraduate students stated that their supervisor showed a positive attitude $(63.6 \%)$, established a relationship of equality and mutual interaction to promote their learning $(50 \%)$, and provided continuous feedback and individualized supervision (36\%). Likewise, graduate students stated that their supervisor showed a positive attitude (80\%), established a relationship of equality and mutual interaction to promote their learning (60\%), and provided continuous feedback and individualized supervision $(60 \%)$.

\section{The Evaluation of the Role of Clinical Instructors}

The fifth domain was focused on the role of the clinical instructors (see the supplementary materials at http:// www.rcjournal.com). According to student evaluations, cooperation between the clinical instructor and staff was considered excellent. Clinical instructors worked with clinical teams and used their pedagogical expertise to support student learning. The relationship between students and clinical instructors was satisfactory because of comfortable experiences at their common meetings. The undergraduate students stated that they felt comfortable in the meetings $(72.7 \%)$ and that these meetings were focused on their learning needs $(63.6 \%)$. The graduate students also stated that they felt comfortable in the meetings $(80 \%)$ and that these meetings were focused on their learning needs $(50 \%)$.

\section{Perceptional Differences Between Undergraduate and Graduate Students}

When perceptions of undergraduate and graduate students were compared in terms of the learning environments of clinical facilities, the content of supervision, and the role of the clinical instructor, we found that ratings of graduate students were generally higher than those of undergraduate students in all domains of clinical facilities (Table 3). According to the Mann-Whitney $U$ test, however, the only statistically significant difference in perception between undergraduate and graduate students was on the statement of the pedagogical atmosphere of clinical facilities. Graduate students gave significantly higher ratings to the learning situations of clinical facilities as multidimensional in terms of content compared to undergraduate students in the program $(P=.043)$. The remaining comparisons relating to the CLE were not statistically significant $(P=.55)$.

\section{Discussion}

To our knowledge, this is the first study to evaluate the perceptions of RT students on the learning environment of clinical facilities affiliated with an RT program at an urban state university, as well as the impact of education level on student perceptions of the CLE of clinical facilities. The results obtained from this study indicated that both graduate and undergraduate RT students gave high median scores to the academic atmosphere of the clinical facilities. We also found that students felt supported and managed in 


\section{Student Perceptions of Clinical Learning Environments}

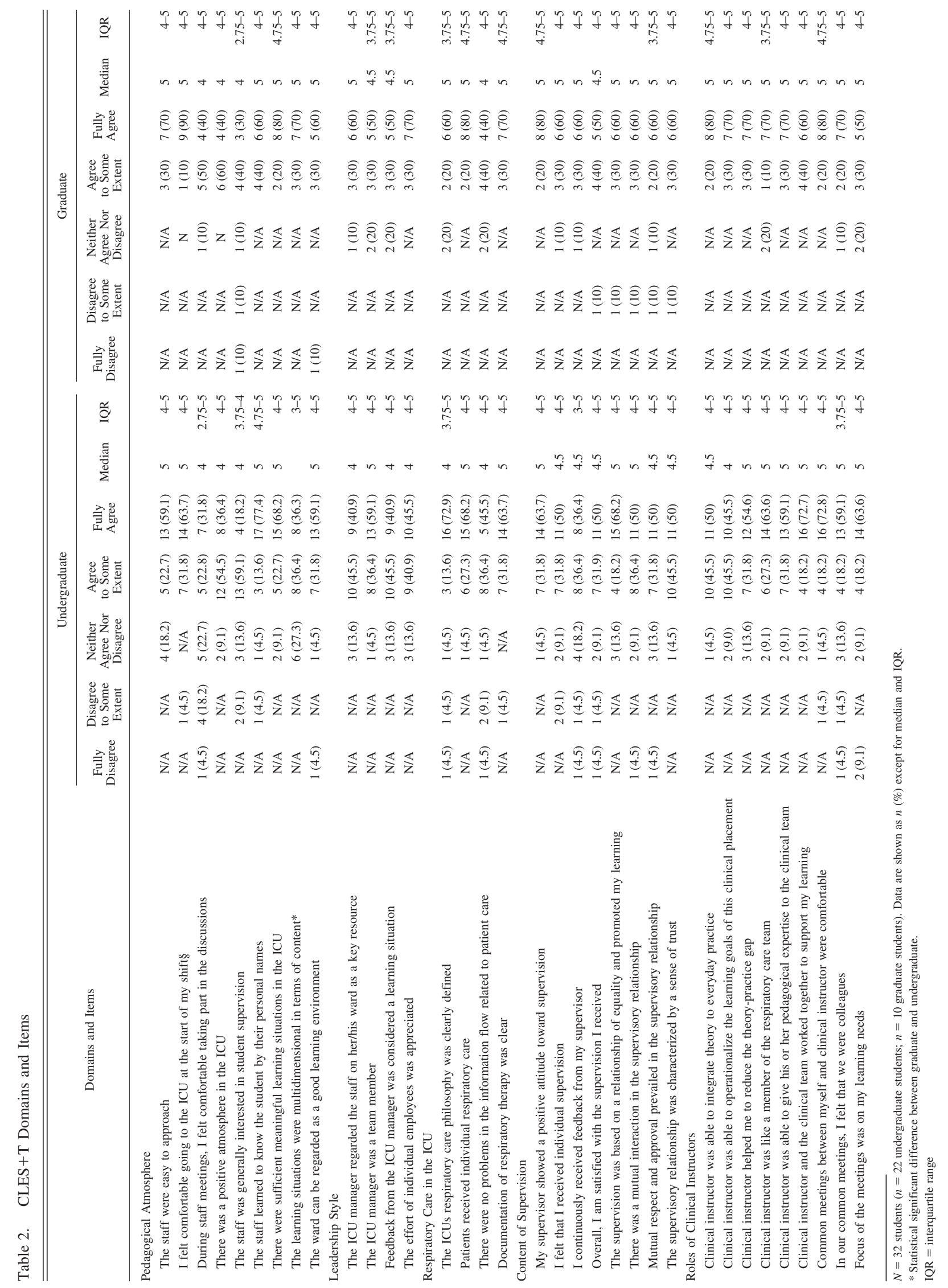


Table 3. Median Scores for Each Domain

\begin{tabular}{lcc}
\hline \hline \multicolumn{1}{c}{ Domain (items) } & $\begin{array}{c}\text { Undergraduate } \\
\text { Median (IQR) }\end{array}$ & $\begin{array}{c}\text { Graduate } \\
\text { Median (IQR) }\end{array}$ \\
\hline Pedagogical atmosphere & $5(4-5)$ & $5(4-5)$ \\
Leadership style & $4(4-4.75)$ & $5(4-5)$ \\
Respiratory care in the ICU & $4.50(4-5)$ & $5(4.25-5)$ \\
Content of supervision & $4.50(4.50-5)$ & $5(4-5)$ \\
Roles of clinical instructors & $5(4.75-5)$ & $5(4-5)$ \\
& & \\
$N=32$ students $(n=22$ undergraduate students; $n=10$ graduate students) & \\
IQR = interquartile range & & \\
\end{tabular}

the clinical practice when they cooperated with the staff. However, they were unsatisfied with the CLE in terms of factors such as multidimensional learning conditions. Another important factor associated with the study was the supervisory relationship, which acted as an important parameter in improving the quality of learning of the students in a clinical facility.

We also found that the highest median scores were given to the domain of the role of the clinical instructor. This suggests that, with an effective clinical instructor, students feel encouraged to overcome obstacles and strive to successfully complete their learning and practice objectives. If the clinical instructor is cooperative, supportive, and knowledgeable, this helps the students integrate theory and practice. Continuous meetings and visits from the instructor help the students academically and support them emotionally.

\section{Evaluation of Clinical Facilities}

The participating students ranked feeling comfortable in the clinical setting as the most important aspect of the academic atmosphere. Another important aspect of the academic atmosphere was a supportive learning environment and cooperative staff. This was consistent with the findings of previous studies conducted in a nursing setting. 19,20 According to these studies, the most important factor in the clinical facility that influenced the academic atmosphere was the presence of reflective and supportive staff as well as a positive CLE. ${ }^{21}$

We found that the interaction of staff within the clinical facility significantly influenced the student's capacity to improve their knowledge and practice. A study conducted by Reynolds ${ }^{22}$ in 1992 reported similar results with the exception that this study stated that students felt uncomfortable in staff meetings. This might be due to the different education levels attained by the clinical instructor in the clinical setting, as concluded by McLeod et al, ${ }^{23}$ who focused on the perceptions of the instructor regarding the importance of the pedagogical atmosphere in a clinical educational environment. Their results showed that the perceptions of instructors varied depending on the effectiveness of the instructors: effective instructors considered pedagogical atmosphere as a crucial component influencing the CLE, whereas ineffective instructors focused on the adequacy of instruction.

The participating students in this study ranked the statement "The staff were generally interested in student supervision." as the lowest. There are 2 critical elements described in various studies attributed to the CLE: the need to appreciate the student and consider them as a part of the respiratory care team; and a supportive staff. Mutual respect and positive regard for others had a significant impact on the confidence of the students according to qualitative studies that have been conducted in the United Kingdom, ${ }^{23}$ Sweden, ${ }^{24}$ Canada $^{25}$ and Ireland. ${ }^{26}$

Another study investigated the perception of students regarding the importance of effective leadership of ward managers. ${ }^{27}$ In that study, students stated that they considered the clinical instructor as a highly significant factor, because the latter helped the former understand the basic and fundamental concepts of clinical practice. This study also showed a similar perception of participating students who held the opinion that an effective clinical instructor was one who believed in giving feedback, good teamwork, and good communication within the staff. As in other studies, the leadership style of the clinical instructor was considered an important aspect in a CLE. ${ }^{27-30}$

The second domain focused on the supervisory relationship of the RT students in the CLE. A majority of participating students reported that they had a supervisor in the clinical facilities; however, this varied according to the clinical facility. Dimitriadou et $\mathrm{al}^{31}$ concluded that a good relationship with clinical instructors resulted in the successful achievement of the clinical learning objectives.

We found that a significant percentage of the students reported a lack of successful private supervision and a high percentage of failed supervisory relationship. This conflicts with the fact that clinical learning plays a vital role in RT education. It also contrasts with the finding that a majority of the students experienced team supervision, a fact contrary to the philosophy and principles of individualization. Price et al, 32 in a qualitative study conducted in 2011, stressed the need for the clinical instructor to be visible and available at regular intervals in the clinical setting.

\section{Perceptional Differences Between Graduate and Undergraduate Students About the CLE}

Information about the difference in perception between graduate and undergraduate students in this study reflected the notion that the level of education might impact the CLE in respiratory therapy. Researchers assumed that graduate students were more comfortable than undergraduate 


\section{Student Perceptions of Clinical Learning Environments}

students because the former had more RT experience across various clinical facilities. Experiencing the profession from different perspectives gives graduate students a chance to explore real-life attributes of the learning environment in clinical facilities. Graduate students have the experience to work and acquire knowledge via communication with other professionals in the clinical setting. These findings provide insights to indicate that graduate students do not depend exclusively on clinical instructors in seeking knowledge about the respiratory care profession.

\section{Implications for Research}

The results obtained from this study can help coordinators of respiratory therapy programs value students' opinions and experiences and more fully appreciate the strengths of their respective programs. Our findings may also help identify areas that require improvement to achieve a successful and effective CLE for respiratory therapy. This study could enlighten clinical supervisors as well as instructors of clinical facilities and directors of clinical education involved in the RT education. These findings may help identify areas that may need manipulation, modification, and improvement in clinical education to create an effective learning environment for students. To our knowledge, this is the first study to evaluate clinical facilities affiliated with a respiratory therapy programs from multiple perspectives. Therefore, it should be considered a significant contribution to the literature, as it focused on various aspects related to the improvement of clinical facilities to foster the clinical learning experience of respiratory therapy students. This study was also important in that it further added to the existing short list of studies conducted in the field of CLE with regard to RT education.

\section{Limitations}

Limitations of this study include the following. First, our convenience sample was selected from only 1 institution. Second, we had a relatively small sample size for comparing different education levels. Third, we focused on the CLE in respiratory care education only; the findings may not be representative for health care professions more broadly. Further research studying multiple disciplines in allied health is needed to determine the effectiveness of CLEs in physical therapy, nursing, occupational therapy, and other health care education programs. Finally, we did not take into account factors like age, previous clinical experience, gender, or ethnicity of the participants; these factors might affect perceptions regarding the CLE.

\section{Conclusions}

Because respiratory therapy is a practice-based profession, it is essential to integrate clinical education into the respiratory care curriculum. Education level may influence students' perceptions about the learning environment of clinical facilities. This study provided information regarding areas for improvement in clinical facilities affiliated with a respiratory care education program at an urban university.

\section{REFERENCES}

1. Alasmari AM. Respiratory therapy students' perceptions of effective teaching characteristics of clinical instructors at an urban university [master's thesis]. Georgia State University, Atlanta, Georgia.

2. Vernon MM, Moore NM, Cummins LA, Reyes SE, Mazzoli AJ, Heboyan V, De Leo G. Respiratory therapy faculty knowledge of and attitudes toward interprofessional education. Respir Care 2017; 62(7):873-881.

3. Bisholt B, Ohlsson U, Engström AK, Johansson AS, Gustafsson M. Nursing students' assessment of the learning environment in different clinical settings. Nurse Educ Pract 2014;14(3):304-310.

4. Bradley P, Postlethwaite K. Setting up a clinical skills learning facility. Med Educ 2003;37(s1):6-13.

5. Carlson E, Idvall E. Nursing students' experiences of the clinical learning environment in nursing homes: A questionnaire study using the CLES + T evaluation scale. Nurse Educ Today 2014;34(7):11301134.

6. Chesser-Smyth PA. The lived experiences of general student nurses on their first clinical placement: a phenomenological study. Nurse Educ Pract 2005;5(6):320-327.

7. Dunn SV. The development of a clinical learning environment scale. J Adv Nurs 1995;22(6):1166-1173.

8. Dunn SV, Hansford B. Undergraduate nursing students' perceptions of their clinical learning environment. J Adv Nurs 1997;25(6):12991306.

9. Fabrigar LR, Wegener DT, MacCallum RC, Strahan EJ. Evaluating the use of exploratory factor analysis in psychological research. Psychol Methods 1999;4(3):272.

10. Fretwell JE. Creating a ward learning environment: the sister's role. Nurs Times 1983;79(34):42.

11. Hall M, McFarlane L-A, Mulholland S. Positive clinical placements: perspectives of students and clinical educators in rehabilitation medicine. Int J Ther Rehabil 2012;19(10).

12. Henderson A, Twentyman M, Eaton E, Creedy D, Stapleton P, Lloyd B. Creating supportive clinical learning environments: an intervention study. J Clin Nurs 2010;19(1-2):177-182.

13. Jarski RW, Kulig K, Olson RE. Clinical teaching in physical therapy: student and teacher perceptions. Phys Ther 1990;70(3):173-178.

14. Leveck ML, Jones CB. The nursing practice environment, staff retention, and quality of care. Res Nurs Health 1996;19(4):331-343.

15. Löfmark A, Wikblad K. Facilitating and obstructing factors for development of learning in clinical practice: a student perspective. J Adv Nurs 2001;34(1):43-50.

16. Singh A, Chopra M, Adiba S, Mithra P, Bhardwaj A, Arya R, et al. A descriptive study of perceived stress among the North Indian nursing undergraduate students. Iran J Nurs Midwifery Res 2013;18(4):340.

17. Saarikoski M, Isoaho H, Warne T, Leino-Kilpi H. The nurse teacher in clinical practice: developing the new sub-dimension to the clinical learning environment and supervision (CLES) scale. Int J Nurs Stud 2008;45(8):1233-1237.

18. Saarikoski M, Leino-Kilpi H. The clinical learning environment and supervision by staff nurses: developing the instrument. Int J Nurs Stud 2002;39(3):259-267.

19. Öhman A, Hägg K, Dahlgren L. A stimulating, practice-based job facing increased stress-clinical supervisors' perceptions of profes- 


\section{Student Perceptions of Clinical Learning Environments}

sional role, physiotherapy education and the status of the profession. Adv Physiother 2005;7(3):114-122.

20. Pearcey PA, Elliott BE. Student impressions of clinical nursing. Nurse Educ Today 2004;24(5):382-387.

21. Rogers JL, Lautar CJ, Dunn LR. Allied health students' perceptions of effective clinical instruction. Health Care Manager 2010;29(1):63-67.

22. Reynolds A. What is competent beginning teaching? A review of the literature. Rev Educ Res 1992;62(1):1-35.

23. McLeod P, Steinert Y, Chalk C, Cruess R, Cruess S, Meterissian S, et al. Which pedagogical principles should clinical teachers know? Teachers and education experts disagree on important pedagogical principles. Med Teach 2009;31(4):e117-e124.

24. Myrick F, Yonge OJ. Creating a climate for critical thinking in the preceptorship experience. Nurse Educ Today 2001;21(6):461-467.

25. Saarikoski M, Warne T. Clinical learning environment and supervision: testing a research instrument in an international comparative study. Nurse Educ Today 2002;22(4):340-349.

26. Salminen L, Stolt M, Saarikoski M, Suikkala A, Vaartio H, LeinoKilpi H. Future challenges for nursing education: a European perspective. Nurse Educ Today 2010;30(3):233-238.
27. Saarikoski M, Warne T, Kaila P, Leino-Kilpi H. The role of the nurse teacher in clinical practice: an empirical study of Finnish student nurse experiences. Nurse Educ Today 2009;29(6):595600

28. Spouse J. Bridging theory and practice in the supervisory relationship: a sociocultural perspective. J Adv Nurs 2001;33(4):512522 .

29. Tompson M, Proctor LF. Factors affecting a clinician's decision to provide fieldwork education to students. Can J Occup Ther 1990; 57(4):216-222.

30. Warne T, Johansson U-B, Papastavrou E, Tichelaar E, Tomietto M, Van den Bossche K, et al. An exploration of the clinical learning experience of nursing students in nine European countries. Nurse Educ Today 2010;30(8):809-815.

31. Dimitriadou M, Papastavrou E, Efstathiou G, Theodorou M. Baccalaureate nursing students' perceptions of learning and supervision in the clinical environment. Nurs Health Sci 2015;17(2):236-242.

32. Price SL. The experience of choosing nursing as a career: narratives from millennial nurses. 2011. Toronto, ON: University of Toronto. 